\title{
You really are too kind: implications regarding friendly submissiveness in trainee therapists
}

\author{
Lylli Cain, ${ }^{1}$ Hana Perkey, ${ }^{2}$ Sabina Widner, ${ }^{3}$ J. Aaron Johnson, ${ }^{4}$ Zachary Hoffman, ${ }^{3}$ Jenelle Slavin-Mulford ${ }^{3}$
}

${ }^{1}$ Gordon F. Derner School of Psychology, Adelphi University, Garden City, NY; ${ }^{2}$ Safe Homes Domestic Violence Center, Augusta, GA; ${ }^{3}$ Department of Psychological Sciences, Augusta University; ${ }^{4}$ Institute of Public and Preventive Health, Augusta University, Augusta, GA, USA

\begin{abstract}
To facilitate patient growth, therapists must immerse themselves in the patient's world while also being able to see what is needed for change. This process requires finding a delicate balance between supporting and pushing patients. Therapists in training are additionally tasked with incorporating supervisors' suggestions with their own views on what is needed to help their patients. Beginning therapists with tendencies to be overly accommodating may struggle

Correspondence: Lylli Cain, Gordon F. Derner School of Psychology, Adelphi University, 1 South Ave, Garden City, NY 11530, USA. Tel.: +17063998004 .

E-mail: lyllicain@mail.adelphi.edu

Citation: Cain, L., Perkey, H., Widner, S., Johnson, J.A., Hoffman, Z., \& Slavin-Mulford, J. You really are too kind: implications regarding friendly submissiveness in trainee therapists. Research in Psychotherapy: Psychopathology, Process and Outcome, 21(2), 72-82. doi: 10.4081 /ripppo.2018.312

Contributions: LC, JSM conceived of the presented idea; HP, JSM acquired the data. LC wrote the manuscript and performed the analytic calculations in consultation with JAJ, JSM, SW. ZH aided in interpreting the results and worked on the manuscript. All authors critically revised the manuscript. JSM supervised the project.

Conflict of interest: the authors report grants from Society for Psychotherapy Research, grants from American Psychological Association, Division 29, during the conduct of the study. to reconcile these competing demands. Thus, the aim of the present work is to explore how trainee friendly submissiveness (FS) interfaces with psychotherapy. Prior to training, clinical graduate trainee $(n=35)$ FS was assessed using the Inventory of Interpersonal Problems-32. Process and outcome data were then collected from each therapist's first training case. Specifically, each trainee was assigned an undergraduate student volunteer with whom they had four non-manualized therapy sessions over the academic semester. After the third session, patients and trainees completed questionnaires assessing session impact and the working alliance, and two expert raters coded third session videotapes for techniques. Following termination, patients rated the overall helpfulness of the therapy. Trainee FS was significantly negatively associated with patient-rated depth, alliance, and overall helpfulness with moderate effects. Findings from a mediation analysis further suggested that trainees with higher FS struggled to focus the therapy in a way that felt productive to patients. Implications for clinical training are discussed.
\end{abstract}

Funding: this study was supported by the Society for Psychotherapy Research Small Research Grants Program and the American Psychological Association (Division 29) Charles J. Gelso Psychotherapy Research Grant. Augusta University has also supported this study through several small grants from the Center for Undergraduate Research and Scholarship, the Office of Faculty Development and Teaching Excellence, the Faculty Research and Faculty Development Grant, the Small Grants Program, and the Student Research Program.

Conference presentations: Trainee therapist friendly submissiveness and the psychotherapy process. Poster presented at the 34th annual Graduate Research Day at Augusta University (AU), Augusta, GA, March 2018. Trainee therapist interpersonal style and the psychotherapy process. Paper submitted for the 25th annual meeting of the Georgia College Counseling Association (GCCA), St. Simons Island, GA, January 2018.

Received for publication: 18 May 2018

Revision received: 10 July 2018.

Accepted for publication: 10 July 2018.

This work is licensed under a Creative Commons Attribution NonCommercial 4.0 License (CC BY-NC 4.0).

(C) Copyright L. Cain et al., 2018

Licensee PAGEPress, Italy

Research in Psychotherapy:

Psychopathology, Process and Outcome 2018; 21:72-82

doi:10.4081/ripppo.2018.312
Key words: Interpersonal circumplex; Friendly submissiveness; Therapist personality.

\section{Introduction}

An overarching goal of psychotherapy is to promote patient growth. This process is complex and requires the therapist to balance goals of affirmation and change (Wachtel, 1993). On the one hand, therapists must immerse themselves in their patients' worlds to understand and empathize. On the other, therapists must be able to step outside of their patients' experiences and critically assess what is needed for change (Kivlighan, Marmarosh, \& Hilsenroth, 2014; Wachtel, 1993). Patients often recognize the need for change (Wachtel, 1993), but also fear it for various reasons. For instance, patients sometimes fear that they will lose a cherished part of themselves, or that their new self will be unrecognizable (CastelnuovoTedesco, 1984, 1989; Wachtel, 1993). However, research shows that when therapists encourage patients to confront 
their fears, psychotherapy is more likely to bring about desired outcomes (e.g., Marks, 1989; Wachtel, 1977, 1991, 1993). Regas, Kostick, Bakaly, and Doonan (2017) have surmised that some therapists who find it difficult to balance their own needs with the needs of others might feel compelled to be overly accommodating with their patients. If therapists are too accommodating, they may find it harder to facilitate patient change.

Friendly submissiveness (FS) is an interpersonal style characterized by tendencies to be overly accommodating, nonassertive, and self-sacrificing (Horowitz, Alden, Wiggins, \& Pincus, 2000). Despite the prevalence of these interpersonal traits among mental health professionals (Bemak \& Chung, 2008), FS is a largely understudied interpersonal style (Kiesler, 1996), particularly in relation to psychotherapy. As such, the aim of the present work is to begin filling this gap by exploring the potential impact of therapist FS on the therapeutic process. We chose to begin this exploration with trainees given that the link between therapist personality and therapeutic process and outcome may be especially salient in therapists with less experience (Chapman, Talbot, Tatman, \& Britton, 2009; Stoltenberg, McNeill, \& Delworth, 1998). Whereas seasoned clinicians may have the insight to manage vulnerabilities associated with their interpersonal style, trainees lack the years of training and personal growth that facilitates such insight. Additionally, seasoned clinicians' familiarity with personality assessment measures often precludes them from taking these measures; indeed, this preclusion may explain the scant research on therapists' personal characteristics (Anderson, Ogles, Patterson, Lambert, \& Vermeersch, 2009; for a review, see Beutler et al., 2004). Finally, identifying trainees' interpersonal styles can help guide efforts to target vulnerabilities that may be amenable to change through early training and supervision.

\section{Conceptualizing friendly submissiveness}

The interpersonal circumplex is a conceptual model that organizes personality into quadrants based on an individual's degree of affiliation and dominance (Alden, Wiggins, $\&$ Pincus, 1990). People who are high on affiliation (i.e., friendly) and low on dominance (i.e., submissive) tend to lack self-confidence, be overly concerned with obtaining others' approval, and have difficulties setting boundaries (Horowitz et al., 2000; Horowitz, Rosenberg, Baer, Ureño, \& Villaseñor, 1988). A previous study on interpersonal problems in depressed young adults indicated that individuals in the friendly and submissive groups experienced more anxiety and separation insecurity (Dawood, Thomas, Wright, \& Hopwood, 2013). Dawood and colleagues (2013) suggest that in the interest of maintaining interpersonal bonds, these individuals may be less likely to engage in social behaviors that could be interpreted as confrontational. The friendly submissive interpersonal style has also been associated with dependent personality disorder
(Horowitz et al., 2000), social anxiety (Weeks, Heimberg, \& Heuer, 2011), and a fearful-avoidant attachment style (Horowitz et al., 2000). These relational difficulties may render it challenging for trainee therapists high in FS to push patients to do the rigorous therapeutic work that drives change. However, individuals with a friendly submissive style also tend to be gifted with interpersonal strengths such as adaptive help-seeking and attunement to subtle interpersonal cues (Bornstein \& Hopwood, 2017). Additionally, they tend to be conscientious in following treatment regimens (Bornstein \& Hopwood, 2017), which might manifest in trainee therapists as greater receptiveness to feedback from supervisors. An important research question is whether and how trainee therapist FS facilitates or impedes the psychotherapy process. In the sections that follow, we will discuss alliance, therapeutic techniques, session depth, and overall helpfulness of the therapy (in this order) as they relate to trainee FS.

\section{Friendly submissiveness and alliance}

A salient predictor of psychotherapy outcome is the extent to which therapists and patients can form a working alliance (e.g., Fluckiger, Del Re, Wampold, Symonds, \& Horvath, 2012; Horvath, Del Re, Fluckiger, \& Symonds, 2011; Norcross \& Wampold, 2011; Safran \& Kraus, 2014; Zilcha-Mano \& Errázuriz, 2017). In fact, therapeutic change has been conceptualized in some literatures as a byproduct of the patient-therapist relationship (Castelnuovo-Tedesco, 1984). Arguably, therapists need to have the facilitative skills to be able to provide the appropriate level of support and affirmation that patients need as they encounter difficulties throughout the therapeutic process. Thus, it is not surprising that therapists with problematic interpersonal styles struggle to build a strong working alliance with their patients (e.g., Ackerman \& Hilsenroth, 2001).

To the authors' knowledge, the relationship between therapist FS and the working alliance has not yet received attention in the empirical literature. Moreover, therapist FS has not been explored in relation to the constituent components of the alliance. Bordin (1979) described the working alliance as a function of the extent to which the patient and the therapist i) develop a strong affective relational bond; ii) mutually agree on the desired outcomes of the therapy (i.e., goals); and iii) mutually agree on the relevance and effectiveness of the methods used to achieve these outcomes (i.e., tasks). Identifying goals can be challenging for trainee therapists for a multitude of reasons. Namely, patients may not be able to articulate their goals, feel comfortable disclosing their true goals, or identify goals that are attainable within the designated timeframe for therapy (Cooper \& McLeod, 2007). Similarly, facilitating patient participation in meaningful tasks is inherently difficult, as it requires instilling hope where patients have often felt hopeless and finding the delicate balance of pushing while also supporting. Confidently and effectively navigating this process while also modeling 
openness to mistakes is understandably challenging for new trainees and may be especially daunting for those high in FS. For one, given that FS is related to difficulties taking initiative (Horowitz et al., 2000) and fear of appearing oppositional, trainees with high FS may not articulate when they feel that tasks and goals need to be modified. Additionally, these trainees may be reluctant to negotiate changes that stray from treatment regimens due to their high levels of conscientiousness (Bornstein \& Hopwood, 2017) and their inclination to be obliging and deferential (Horowitz et al., 2000) to the supervisor. Overall, it seems that trainees with higher FS may lack the confidence (Horowitz et al., 1988, 2000) and flexibility necessary to respond to a patient's needs by negotiating relevant changes. Problems navigating tasks and goals could negatively impact the bond aspect of the alliance if ruptures are not managed effectively, or if the patient feels unable to respect or trust the therapist. However, given previous findings that therapist friendliness and related attributes such as warmth, interest, and openness (Ackerman \& Hilsenroth, 2003) are positively associated with a helping alliance, trainees high in FS may be perceived as more likeable by patients and have an easier time forming a therapeutic bond. Taken together, these findings suggest that the task and goal portions of alliance may suffer when trainee FS is high, but the overarching relationship with bond is less clear.

\section{Use of therapeutic techniques}

Learning how to implement therapeutic techniques is a critical part of trainees' educational experience. As noted in Hill, Stahl, and Roffman (2007), helping skills training provides new therapists with a framework for understanding the therapeutic process and a sense of security when they are stuck, flustered, or unsure of what might be most productive or helpful in a session (p. 365). Notably, the Hill model $(2009,2014)$ highlights the importance of empathy and warmth in facilitating the therapeutic process. In a recent systematic review, it was suggested that therapists' personal characteristics interact with their use of therapeutic interventions to predict psychotherapy outcomes (Lingiardi, Muzi, Tanzilli, \& Carone, 2018); however, the relationship between therapist interpersonal style and technique usage has not been extensively researched.

On the one hand, trainees may use techniques more frequently as FS increases, considering that individuals high in FS see themselves as obliging, accommodating, and deferential (Horowitz et al., 2000), traits which may result in a desire to appease the supervisor. Furthermore, FS individuals' conscientiousness in adhering to treatment regimens and their propensity toward adaptive help-seeking (Bornstein \& Hopwood, 2017) might lead trainees high in FS to utilize more of the techniques they learn throughout training. Conversely, trainees with high FS may avoid using techniques aimed at facilitating patient exploration, insight, and action given that these tech- niques often involve allowing the patient to experience uncomfortable feelings, challenging the patient to critically evaluate his or her beliefs, and helping the patient to implement difficult changes (Hill \& Kellems, 2002), all of which may feel too confrontational to the trainee high in FS. Because these trainees are presented with the competing tasks of accommodating the supervisor's recommendations and avoiding the provocation of tense and uncomfortable interactions with the patient, it is unclear how a friendly submissive interpersonal style might impact technique usage.

\section{Session depth}

The extent to which therapists and patients perceive therapeutic sessions as powerful and effective, or deep (Stiles \& Snow, 1984), plays an integral role in psychotherapy. Deeper session ratings have been positively correlated with higher likelihood for patient return after intake (Tryon, 1990), a stronger working alliance (Kivlighan et al., 2014; Mallinckrodt, 1993), and greater resolution of patient concerns (Mallinckrodt, 1993). Studies have shown that deeper session ratings are also positively associated with the use of psychodynamic-interpersonal techniques (e.g., Pesale \& Hilsenroth, 2009), which include but are not limited to: exploring uncomfortable feelings, encouraging the patient to experience and express feelings in the therapy session, and addressing patient avoidance (Hilsenroth, Blagys, Ackerman, Bonge, \& Blais, 2005). As discussed above, trainees high in FS may avoid using these techniques due to fear that the patient, unable to tolerate the discomfort these conversations invoke, will withdraw from the therapeutic relationship. Moreover, consistent with previous work linking FS with sensitivity to emotional cues (Bornstein \& Hopwood, 2017), trainees with high FS may be more likely to monitor patients' reactions when they do implement challenging techniques. If the reaction appears to be negative, the trainee may recoil. Unless the trainee helps the patient to process perceived ruptures, both the alliance and depth of the session may suffer.

\section{The present study}

To the authors' knowledge, no studies have explored therapist FS as it relates to the psychotherapy process or outcomes. Thus, the goal of the present study is to examine how trainee FS relates to session process (i.e., depth, alliance, and technique usage) as well as to patients' overall assessment of the helpfulness of the therapy. Because high FS may be especially problematic for trainees who have less experience navigating new relational dynamics, the present study will utilize trainee therapists. Our hope is that encouraging a greater understanding of trainee FS will help us to provide better training and supervision experiences for trainees with friendly submissive tendencies.

In line with previous research showing that patients 
and therapists make judgments about therapy based on different factors (Kivlighan et al., 2014), we will present alliance and depth ratings from both patients and trainees. Moreover, technique usage will be based on observer ratings. As outlined above, we predict a negative association between trainee FS and the task and goal components of the alliance, as navigating these processes requires a level of self-confidence and flexibility that is often lacking in individuals with high FS. Given that trainees with high FS may be perceived as more likeable but less reputable to the patient, we cannot propose a directional hypothesis for the bond component of the alliance. Likewise, due to the conflicting considerations that trainees with high FS may be more likely to follow treatment regimens but may avoid implementing challenging techniques, we cannot propose a directional hypothesis for technique usage. However, in line with previous evidence that session depth corresponds to the use of challenging techniques, we predict a negative association between trainee FS and session depth. Finally, because trainees may have difficulties negotiating tasks and goals and promoting session depth as FS increases, we predict that greater trainee FS will be associated with lower patient ratings of overall therapy helpfulness. If any of the individual process variables (i.e., bond, task, goal, overall alliance, session depth, techniques) are significantly correlated with trainee FS, we will run analyses to see whether any of these variables mediate the relationship between trainee FS and patient ratings of overall helpfulness of the therapy.

\section{Materials and Methods}

\section{Participants}

This study was approved by the university's ethics board (Institutional Review Board Committee B of Augusta University, 611630-10, 2013). The sample included 4 cohorts of graduate trainees $(n=42)$ enrolled in a clinical psychology program. After the first semester, $17 \%$ ( $n$ $=7$ ) of the sample either switched out of the clinical track to an experimental track, withdrew from the program, or were asked to leave the program. These participants were excluded from analyses because they did not complete the therapy course. The remaining participant group $(n=35)$ was $80 \%$ female with a mean age of 24 years $(S D=5.09)$. The racial composition of the sample was $66 \%$ European American, 17\% African American, 3\% Asian American, $9 \%$ Hispanic, and $6 \%$ other. Compared to $87 \%$ of mental health professionals (Orlinsky, Schofield, Schroder, \& Kazantzis, 2011), only $34 \%$ of trainee therapists in the present sample endorsed having received therapy. Trainees reported a mean time spent in therapy of 7.29 months and a range of 3 months to 8.42 years.

Volunteer undergraduate students from the same university served as therapy patients. The undergraduates who consented to participate in the therapy sessions were currently enrolled in a course focused on personal growth and exploration. These students received course credit for participating in the sessions and writing a reflection essay about their experience. None of these undergraduates knew the researchers in this project, and their professor was not provided any information about the therapy sessions except that the students participated. The patient group $(n=35)$ was $69 \%$ female, $43 \%$ European American, 34\% African American, 14\% Asian American, 6\% Hispanic, and $3 \%$ other. The mean age of the group was 21 years $(S D=3.91)$. Twenty-three percent of patients reported previous therapy experience with a mean time spent in therapy of 8.87 months with a very large range of 1 month to 18 years.

\section{Procedures}

\section{Assessment of Trainee Interpersonal Problems}

At the beginning of their graduate training $\left(2^{\text {nd }}\right.$ day of class of the $1^{\text {st }}$ semester), all trainees completed a multimethod assessment which included the Inventory of Interpersonal Problems-32 (IIP-32; Horowitz et al., 2000). A research assistant (RA) unaffiliated with the program collected informed consent and administered, de-identified, and scored the IIP-32. All student responses were kept confidential and were not shared with anyone in the program (including the professor of the course). (See Trainee Interpersonal Problems for a description of the IIP-32).

\section{Therapy sessions}

In their second semester, all clinical graduate students took an introductory therapy course. This four-credit course focused on therapeutic technique with curriculum based on Hill's three-stage model of helping as presented in Helping Skills: Facilitating Exploration, Insight, and Action, Third Edition (2009). As part of the requirements of the course, each trainee was assigned an undergraduate student volunteer with whom they had four non-manualized therapy sessions throughout the academic semester. The first session was a 1.5-hour intake and the remaining three sessions were 45 minutes and focused on whatever issues patients presented. Patients were told that they could use the sessions to work on whatever felt most important to them at the time. However, they were instructed not to share concerns which would necessitate an intervention by a licensed professional such as suicidal or homicidal ideation or child or elder abuse. Common presenting problems included difficulties in interpersonal relationships, anxiety related to school performance, and concerns regarding choosing a career path.

All sessions were videotaped, and all trainees received supervision from Jenelle Slavin-Mulford, the course instructor. Dr. Slavin-Mulford is a licensed psychologist and tenured associate professor in the graduate program. She completed training in assessment and psychotherapy at the predoctoral (APA approved), internship (from Harvard 
Medical School staff, APA approved), and postdoctoral level. In addition to teaching the introduction to psychotherapy course, she teaches psychopathology and personality assessment and remains clinically active through her work as a faculty clinician at the university's counseling center.

Following sessions one, two, and four, trainees received 1.5 hours of group supervision (2-3 trainees per group). In addition, students received 1.5 hours of individual supervision following session 3. Supervision focused heavily on the review of video-recorded case material with emphasis on case conceptualization and clinical interventions. For all students, this was the first training case they were assigned.

\section{Post-session evaluation}

At the end of the third therapy session, patients and trainees filled out the Session Evaluation Questionnaire (SEQ; Stiles \& Snow, 1984) and the Working Alliance Inventory (WAI; Horvath \& Greenberg, 1989). In addition, the third session videotapes were rated for technique use by two trained raters using the Helping Skills Measure (HSM; Hill \& Kellems, 2002). At the end of the fourth session, patients rated the overall helpfulness of the therapy. See Post-Session Measures for a description of the measures used in this assessment.

\section{Measures}

\section{Trainee interpersonal problems}

The Inventory of Interpersonal Problems-32 (IIP-32; Horowitz et al., 2000). The IIP-32 measures distress related to eight domains of problematic interpersonal behavior. The inventory uses 32 first-person statements to which individuals respond on a Likert-type scale anchored from (1) not at all to (4) extremely. Items include statements representing behaviors that are viewed as difficult to perform with others (e.g., It is hard for me to tell a person to stop bothering $m e$ ) and those that are perceived as too frequent in the respondent's interpersonal relationships (e.g., I want to be noticed too much). The following three subscales of the IIP-32 were used in the current study and were combined to form the construct of FS: Nonassertive, Overly Accommodating, and Self-Sacrificing. This merging is consistent with Horowitz and colleagues (2000), who grouped these subscales together in the Friendly Submissive quadrant of the interpersonal circumplex. The Nonassertive subscale reflects an interpersonal style characterized by avoidance of confrontation or use of social power, a lack of self-confidence and self-esteem, and a desire to withhold personal wishes or goals from others. The Overly Accommodating subscale is characterized by inoffensiveness, inexpression of anger to avoid offending others, and high manipulability. The Self-Sacrificing subscale reflects an interpersonal style characterized by a pronounced lack of personal boundaries and problematically high levels of altruism (Horowitz et al., 2000). The IIP is normed on a national standardization sample of 800 adults (aged 18-89) representative of the U.S. population (Horowitz et al., 2000). All subscales are reported in T-Scores. Internal consistency for the Nonassertive subscale, the Overly Accommodating subscale, and the Self-Sacrificing subscale were $0.83,0.70$, and 0.78 , respectively (Horowitz et al., 2000). The test-retest reliability coefficients were $0.80,0.80$, and 0.65 , respectively, over a median 7-day period (Horowitz et al., 2000).

\section{Post-session measures}

Session Evaluation Questionnaire-Depth (SEQ; Stiles $\&$ Snow, 1984). The SEQ-Depth subscale utilizes a 1 to 7 semantic differential scale to assess the extent to which patients and therapists perceived the psychotherapy session as powerful or weak, valuable or worthless, deep or shallow, full or empty, and special or ordinary. In a sample of outpatients at a university-based community clinic, Cronbach's alpha for depth was 0.86 (Ackerman, Hilsenroth, Baity, \& Blagys, 2000). In the present study, Cronbach's alpha for patient- and therapist-rated Depth were 0.83 and 0.90 , respectively.

The Working Alliance Inventory (WAI; Horvath \& Greenberg, 1989). The WAI assesses the patient-therapist relationship in terms of a three-part framework (i.e., Bond, Task, Goal) established by Bordin (1979). Bond items address patients' levels of trust, regard, and confidence. Goal items assess agreement on overall therapeutic objectives. Task items assess belief that in-therapy practices are effective and important. The inventory uses 36 first-person statements about the patient-therapist alliance in each of these areas (e.g. I feel uncomfortable with [patient/therapist]) to which individuals respond on a Likert-type scale anchored from (1) never to (7) always. In a sample of counselor-client dyads engaged in short-term counseling, Cronbach's alpha ranged from 0.85 to 0.88 for clients; for the counselors, Cronbach's alpha was 0.68 for Bond, 0.87 for Goal, and 0.82 for Task. In the present study, Cronbach's alpha for patient-rated Bond, Goal, Task, and the combined alliance score were $0.72,0.80,0.83$, and 0.91 , respectively; trainee-rated Bond, Goal, Task, and Combined Alliance were $0.63,0.76,0.82$, and 0.88 .

Helping Skill Measure (HSM; Hill \& Kellems, 2002). The HSM captures basic therapy skills using 13 Likert-type items anchored from (1) strongly disagree to (5) strongly agree. This measure consists of the following three subscales: exploration (4 items), insight (4 items), and action (5 items). The primary focus of the exploration stage is to develop an understanding of the patient and his or her presenting problems. Items include: (1) Asked question to help the patient explore what he/she was thinking or feeling; (2) Encouraged the patient to express what he/she was thinking or feeling; (3) Helped the patient think about his/her concerns; and (4) Encouraged the patient to experience his/her feelings. In the insight stage, therapists assist patients in finding new ways of understanding their problems and being aware of how they might be contributing to these 
problems. Items include: (1) Encouraged the patient to challenge his/her beliefs; (2) Helped the patient become aware of contradictions in his/her thoughts, feelings, and behaviors; (3) Helped the patient understand the reasons behind his/her thoughts, feelings, and behaviors; and (4) Helped the patient gain a new perspective on his/her problem. The goal of the action stage is for the therapist and the patient to integrate information gathered during the exploration and insight stages and to contemplate what it would be like for the patient to make a change regarding a problematic behavior or situation. If the patient is open to making a change, the therapist helps the patient to enact that change. Items include: (1) Helped the patient think about changes he/she could make in his/her life; (2) Taught the patient specific skills to deal with his/her problems; (3) Helped the patient identify useful resources; (4) Helped the patient figure out how to solve a specific problem; and (5) Discussed with the patient specific things he/she could do to make change happen.

HSM Training. The instructor and a master's level research assistant trained on the HSM by reading Hill (2009) and Hill and Kellems (2002), practicing coding on 17 videotaped sessions, and having team discussions about the rating categories. After completing the training, the two raters watched each trainee's third session videotape in its entirety and then immediately rated the session independently using the HSM. The raters were blind to the participants' initial assessment and post-session selfreport data. Regular reliability meetings were held during the coding process to prevent rater drift. Intraclass correlation coefficient (ICC) two-way random-effect models with Spearman-Brown corrections were calculated for the exploration $[\operatorname{ICC}(2,2)=0.64]$, insight $[\operatorname{ICC}(2,2)$ $=0.86]$, and action $[\operatorname{ICC}(2,2)=0.86]$ subscales on the HSM. Shrout and Fleiss (1979) report the magnitude for interpreting ICC values where poor $<0.40$, fair $=0.40$ 0.59 , good $=0.60-0.74$, and excellent $>0.74$. In the current sample, five percent $(n=2)$ of trainees did not videotape their session, and thus, the raters could not complete the HSM. These trainees were excluded from the analysis of therapeutic techniques.

Patient Helpfulness Rating. Patient perception of the overall helpfulness of the therapy was assessed using a single Likert-type item anchored from (1) not at all helpful to (7) extremely helpful: Please think about all 4 of the sessions you attended. Overall, how helpful was this therapy experience for you personally? This question relates to how much you feel you grew as a person or were helped with your presenting problem. It is NOT related to obtaining course credit or learning about the field of psychology.

\section{Results}

Assessment means and standard deviations can be found at the bottom of Table 1. Shapiro-Wilk tests indicated that all variables were normally distributed, except for patient ratings of depth and overall helpfulness and observer ratings of trainee use of action techniques. Patient ratings of depth and overall helpfulness were negatively skewed, and observer ratings of action were positively skewed.

\section{Friendly submissiveness and alliance}

We ran Pearson correlations to examine the relationship between trainee FS and alliance subscales and the combined alliance score. Consistent with hypotheses, patient-rated task $(r=-0.41, p<0.05)$ and goal $(r=-0.35, p$ $<0.05)$ were significantly negatively correlated with trainee FS. Patient-rated bond $(r=-0.40, p<0.05)$ and overall alliance $(r=-0.42, p<0.05)$ were also negatively correlated with trainee FS. Using Cohen's (1988) criteria, these effects are considered moderate $(0.50 \geq \mathrm{r} \geq 0.30)$. None of the correlations with trainee-rated bond, task, goal, or alliance were significant (Table 1).

\section{Friendly submissiveness and depth}

As hypothesized, Pearson correlations revealed that patient-rated depth $(r=-0.47, p<0.01)$ was significantly negatively associated with trainee FS with moderate effects (Cohen, 1988). Trainee-rated session depth was not significantly correlated with trainee FS (Table 1).

\section{Friendly submissiveness and technique use}

None of the observer ratings of trainee usage of exploration, insight, or action techniques were significantly correlated with trainee FS (Table 1).

\section{Friendly submissiveness and patient-rated helpfulness}

Our hypothesis regarding trainee FS and patient helpfulness ratings was supported. Pearson correlations showed that patient-rated helpfulness $(r=-0.45, p<0.01)$ was significantly negatively correlated with trainee FS with moderate effects (Cohen, 1988) (Table 1).

\section{Mediation analyses}

Following Baron and Kenny's (1986) guidelines, a series of regressions was computed to test whether overall patient-rated bond, task, goal, overall alliance, or session depth mediated the association between trainee FS and patient-rated helpfulness. Trainee-rated process measures and observer-rated technique usage were excluded from mediation analyses, as none of these variables were found to have a significant correlation with trainee FS or patientrated helpfulness. Of the variables tested, patient-rated task and goal were found to be significant mediators.

Patient-rated task was regressed on trainee FS ( $\beta=$ $0.41, t(34)=-2.60, p<0.05)$. Next, patient-rated helpfulness was regressed on trainee FS $(\beta=-0.45, t(34)=$ $-2.91, p<0.01)$. Finally, patient-rated helpfulness was regressed on both patient-rated task $(\beta=0.43, t(34)=2.72$, 
$p<0.05)$ and trainee FS $(\beta=-0.28, t(34)=-1.78, p=$ $n s)$. The relationship between trainee FS and patient-rated helpfulness was weaker in the third equation $(\beta=-0.28)$ than in the second equation $(\beta=-0.45)$, and trainee FS was no longer a significant predictor in the third equation, indicating mediation (Sobel's $z=-2.12, p<0.05$ ). These findings indicate that patient-rated task significantly mediated the association between trainee FS and patientrated helpfulness. The results from these tests are reported in Figure 1.

Patient-rated goal was regressed on trainee FS $(\beta=$ $0.35, t(34)=-2.12, p<0.05)$. Patient-rated helpfulness

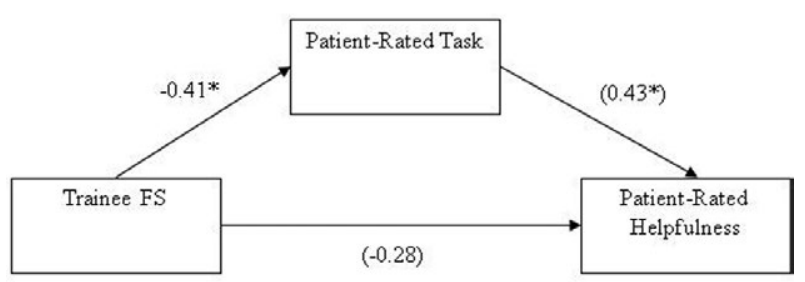

Figure 1. Patient-rated task mediated the relationship between trainee friendly submissiveness and patient-rated helpfulness. The Betas for the mediated path are in parentheses. *P $<$ 0.05. ** $\mathbf{P}<0.01$. was then regressed on trainee FS $(\beta=-0.45, t(34)=-2.91$, $p<0.01)$. Last, patient-rated helpfulness was regressed on both patient-rated goal $(\beta=0.59, t(34)=4.46, p<$ $0.05)$ and trainee FS $(\beta=-0.25, t(34)=-1.88, p=n s)$. The relationship between trainee FS and patient-rated helpfulness was weaker in the third equation $(\beta=-0.25)$ than in the second equation $(\beta=-0.45)$, and trainee FS was no longer a significant predictor in the third equation, indicating mediation (Sobel's $z=-2.05, p<0.05$ ). Thus, patient-rated goal significantly mediated the association between trainee FS and patient-rated helpfulness. The results from these tests are reported in Figure 2.

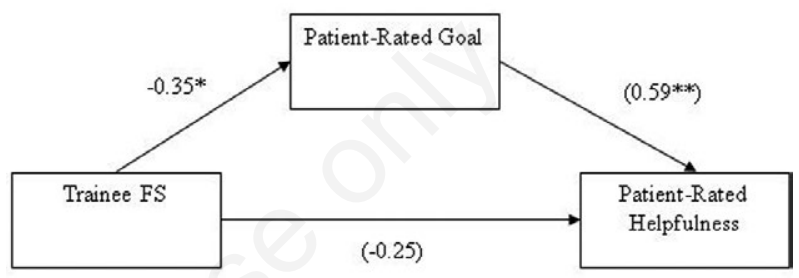

Figure 2. Patient-rated goal mediated the relationship between trainee friendly submissiveness and patient-rated helpfulness. The Betas for the mediated path are in parentheses. $* \mathbf{P}<0.05$. **P $<0.01$.

Table 1. Correlations and Descriptive Statistics.

\begin{tabular}{|c|c|c|c|c|c|c|c|c|c|c|c|c|c|c|c|}
\hline Variables & 1 & 2 & 3 & 4 & 5 & 6 & 7 & 8 & 9 & 10 & 11 & 12 & 13 & 14 & 15 \\
\hline 1. Trainee FS & - & & & & & & & & & & & & & & \\
\hline 2. Patient Bond & $-0.40^{*}$ & - & & & & & & & & & & & & & \\
\hline 3. Patient Task & $-0.41 *$ & $0.70^{* *}$ & - & & & & & & & & & & & & \\
\hline 4. Patient Goal & $-0.35^{*}$ & $0.64 * *$ & $0.71^{* *}$ & - & & & & & & & & & & & \\
\hline 5. Patient Alliancea & $-0.42 *$ & $0.87 * *$ & $0.90^{* *}$ & $0.90 * *$ & - & & & & & & & & & & \\
\hline 6. Trainee Bond & -0.27 & -0.09 & -0.02 & -0.05 & -0.07 & - & & & & & & & & & \\
\hline 7. Trainee Task & -0.14 & 0.13 & $0.35^{*}$ & 0.15 & 0.22 & $0.34 *$ & - & & & & & & & & \\
\hline 8. Trainee Goal & -0.08 & -0.00 & 0.27 & 0.20 & 0.18 & $0.53 * *$ & $0.80 * *$ & - & & & & & & & \\
\hline 9. Trainee Allianceb & -0.20 & 0.01 & 0.23 & 0.11 & 0.12 & $0.77 * *$ & $0.83 * *$ & * $0.92 * *$ & - & & & & & & \\
\hline 10. Patient Depth & $-0.47 * *$ & $0.60^{* *}$ & $0.78 * *$ & $0.51^{* *}$ & $0.70 * *$ & 0.01 & 0.20 & 0.04 & 0.09 & - & & & & & \\
\hline 11. Trainee Depth & 0.26 & -0.20 & -0.17 & -0.27 & -0.24 & -0.02 & 0.03 & -0.06 & -0.02 & -0.01 & - & & & & \\
\hline 12. Exploration & 0.01 & 0.19 & -0.00 & 0.03 & 0.08 & 0.05 & 0.09 & 0.00 & 0.06 & 0.21 & 0.30 & - & & & \\
\hline 13. Insight & 0.22 & 0.16 & -0.00 & 0.22 & 0.16 & -0.15 & -0.30 & -0.26 & -0.28 & 0.01 & 0.30 & $0.39^{*}$ & - & & \\
\hline 14. Action & 0.02 & -0.06 & -0.12 & 0.13 & -0.00 & 0.04 & -0.33 & -0.09 & -0.14 & $-0.39 * *$ & $*-0.37 *$ & $*-0.11$ & -0.03 & - & \\
\hline 15. Patient Helpfulness & $-0.45^{* *}$ & $0.60^{* *}$ & $0.54 * *$ & $0.68 * *$ & $0.68 * *$ & -0.11 & 0.12 & -0.09 & -0.04 & $0.46^{* *}$ & $*-0.29$ & -0.15 & 0.14 & 0.05 & - \\
\hline $\mathrm{M}$ & 56.82 & 70.13 & 71.83 & 69.84 & 70.65 & 62.29 & 59.29 & 55.46 & 59.01 & 5.94 & 4.74 & 3.15 & 2.31 & 1.65 & 6.26 \\
\hline SD & 11.15 & 6.89 & 8.09 & 8.32 & 6.93 & 8.79 & 7.35 & 7.90 & 6.69 & 0.98 & 1.04 & 0.48 & 0.58 & 0.63 & 0.74 \\
\hline
\end{tabular}

Note. Sample size is constant for all variables, $n=35$, except for Exploration, Insight, and Action subscales, $n=33 . r \geq 0.50=$ large effect size, $r \geq .30=$ medium effect size, $r \geq 0.10=$ small effect size (Cohen, 1988). ${ }^{*} \mathrm{p}<.05 * * \mathrm{p}<.01$.aPatient Alliance was computed by averaging Patient Bond, Patient Task, and Patient Goal.bTrainee Alliance was computed by averaging Trainee Bond, Trainee Task, and Trainee Goal. 


\section{Discriminant validity}

To assess whether the results regarding patient alliance and helpfulness could be explained by interpersonal problems more broadly as opposed to FS specifically, we examined correlations between these measures and each of the eight IIP-32 subscales. Importantly, the only subscales with statistically significant correlations with patient-rated alliance and helpfulness were the three subscales comprising the FS quadrant (i.e., Nonassertive, Overly Accommodating, Self-Sacrificing). Thus, while the IIP-32 general factor also showed a significant correlation with these patient-level measures, our findings suggest that this relationship is driven by trainee FS.

\section{Discussion}

To the authors' knowledge, this study is the first to examine the relationship between trainee therapist FS and psychotherapy process and outcome. We collected data from clinical students' first training case in graduate school. Here we explored alliance, session depth, technique usage, and patient reports of feeling that the therapy overall was helpful. Expanding on previous research that has identified therapists' interpersonal skills as a strong predictor of patient outcome (e.g., Anderson, Crowley, Himawan, Holmberg, \& Uhlin, 2016; Anderson et al., 2009), we found that as trainee FS increased, patients' perception of the helpfulness of the therapy as a whole significantly and robustly declined. Moreover, patient ratings of all facets of the alliance and session depth significantly decreased with moderate effects while amount of technique usage did not vary. Moreover, mediation analyses revealed that the task and goal portions of the alliance mediated the association between trainee FS and patient ratings of overall therapy helpfulness. Thus, it appears that as FS increases, beginning trainees have more difficulty working with patients to develop mutually agreed upon goals and effectively navigating the therapeutic process in the context of brief, non-manualized therapy. Interpretations of these findings and implications for therapist training and supervision are discussed below.

Although previous research has demonstrated that therapist interpersonal warmth predicts better alliances (e.g., Dinger, Zilcha-Mano, McCarthy, Barrett, \& Barber, 2013), our findings suggest that the combination of warmth and submissiveness at higher levels may impede the alliance. At first glance, these results seem dubious given that many of the qualities associated with FS characterize the quintessential psychotherapist, who is relationally oriented, receptive to interpersonal cues, and concerned with the welfare of others. However, we suspect that characteristics associated with FS, when present at higher levels, might lead patients to doubt the therapist's ability to facilitate a meaningful therapeutic experience. Indeed, findings from our mediation analysis suggest that trainees with higher FS may struggle to focus and navigate the therapy in a way that feels productive to the patient. These trainees may have felt less confident in developing a direction for the therapy, especially given that treatments were non-manualized and thus required the trainees to apply what they were learning with less imposed structure. It is important to note that trainees were restricted to providing therapy in four sessions. The brevity of this intervention means that it was imperative for the trainees to quickly develop mutually agreed upon tasks and goals with the patient. Moreover, therapists and their patients sometimes have different notions of what constitutes meaningful tasks and goals. Trainees with higher levels of FS may have been more reluctant to discuss these differences for fear of appearing oppositional. In this same vein, trainees who are too accommodating, too sensitive to emotional cues, and too eager to gain the patient's approval may have had difficulty tolerating patient distress; these trainees may have evaded discourse that they expected would accentuate or evoke patient experiences of negative emotionality. This possibility may also explain our finding that patient ratings of session depth dropped with increasing levels of trainee FS. As McCullough and colleagues (2003) note, the richness of the therapy depends partly on the therapist's capacity to avoid the common tendency to move away from feeling and lighten up (p. 172). Developing this skill may be especially useful for trainees with higher FS if they fear upsetting the patient or tend to retreat from tension in the therapeutic relationship.

However, it is important to note that our findings cannot be explained by trainees implementing fewer challenging techniques, as frequency of technique usage was not significantly related to trainee FS. Although quality of technique usage was not coded, we suspect that trainees implemented techniques less effectively as FS increased. This speculation is supported by our finding that trainee FS was inversely correlated with patient ratings of the task component of the alliance. Taken together, these findings suggest that as FS increases, trainees continue to implement techniques but may do so less confidently, less effectively, and with less buy-in from their patients.

It is also worth noting that patient-rated alliance and patient-rated depth were significantly correlated with a large effect size (Cohen, 1988). This interdependence is consistent with findings in the literature suggesting that a secure attachment with the therapist is a precondition to the intense therapeutic work that drives session depth (e.g., Mallinckrodt, Porter, \& Kivlighan, 2005). A therapist who actively listens and responds to their patient's thoughts and feelings in a way that inspires further disclosure, feelings of security, and a collaborative partnership is equipped to provide patients with a meaningful and corrective emotional experience. If unmitigated by selfawareness and effective training, a strong friendly submissive interpersonal style could inhibit these important 
expressions of empathy which foster both session depth and a strong therapeutic alliance.

Diverging from the pattern of results seen with patient ratings, trainee FS and trainee process ratings were not significantly associated in our sample. Moreover, patient overall ratings of the alliance were not associated with trainee overall alliance, nor were patient- and therapistrated depth ratings significantly correlated. These discrepancies seem odd in light of prior research suggesting that therapist and patient ratings of alliance and session depth are interrelated and interdependent (e.g., Kivlighan, 2007; Kivlighan et al., 2014). One possible explanation for this finding is that individuals with more extreme interpersonal styles have less awareness of their interpersonal strengths and weaknesses. Thus, trainees higher in FS may have not been privy to the ways in which their interpersonal style might impact the therapy. As Bornstein and Hopwood (2017) pointed out, traits associated with FS can be expressed in both maladaptive and adaptive ways. In fact, the interpersonal strengths associated with FS (e.g., sensitivity to interpersonal cues) are often adaptive in academia and in social settings. FS individuals are likely to be reinforced for their behavioral tendencies through positive outcomes (e.g., good grades, approval from authority figures, satisfying relationships) attained in these settings. Unless trainees gain insight into the strengths and limitations associated with their interpersonal style, they have no reason to believe that the outcomes are any different in therapy than in other settings. Alternatively, higher levels of FS may correspond with trainee reluctance to report problems with therapy, particularly if they felt that revealing their shortcomings would render disapproval from the supervisor. However, it is worth noting that trainees as a whole rated sessions as lower on bond, task, goals, overall alliance, and depth than did patients.

Findings from the current study should be interpreted with consideration of the following limitations. First, a sample size of 35 does not provide sufficient power to observe all the potentially significant relationships that may exist in our data and may also limit generalizability. Second, we cannot determine whether relationships were causal based on correlations and mediational analyses. Third, patient ratings of the overall helpfulness of the therapy were not normally distributed and were generally high; it would be interesting to see how trainee FS varies across a wider range of helpfulness ratings. Fourth, we did not examine whether FS relates to trainees' response to supervision. A future direction for this research could be to investigate how FS impacts experiences in supervision, such as a trainees' receptivity to constructive criticism. Fifth, the present study focused on trainees in their first experience providing therapy, and therapy was limited to four sessions. On the one hand, this approach lends itself to greater internal validity, as our findings cannot be explained by differences in training experiences. On the other hand, our findings may not be generalizable to more seasoned clinicians, long-term treatment, or treatment in a naturalistic setting. Thus, we encourage future research to expand this work to clinicians working in the community. The first step to conducting this research would be to recruit practicing clinicians, which presents a greater challenge than recruiting trainees. Compared with academic institutions, which are reliable sources of potential participants, other clinical sites may be less likely to have the infrastructure to support consistent data collection, and clinicians may have less time and incentive to participate. However, researchers have had some success recruiting clinicians from inpatient treatment institutions (e.g., Saarnio, 2011; Topolinski \& Hertel, 2007) and psychotherapist directories (e.g., Topolinski \& Hertel, 2007). Beyond initial recruitment procedures, we also suggest excluding psychotherapists who have taken, administered, or are otherwise knowledgeable about the framework of the IIP.

Finally, because therapy is a relational process (Wachtel, 2008), we encourage researchers to further examine how therapist and patient variables interact with one another and with the psychotherapy process. A strength of the present study was its multimethod approach to data collection. Comparing patient and trainee ratings of session depth and the alliance as they relate to trainee selfreported FS revealed that trainees may lack awareness of the interpersonal factors that impact the patient's experience of the therapy. Importantly, had patient ratings not been available for analysis, we would have concluded that trainee FS was related to neither session depth nor the alliance. For these reasons, we urge researchers to continue to implement and advocate multimethod approaches and to expand the current work by examining the interaction of therapist FS with various patient variables (e.g., patient interpersonal style).

\section{Conclusions}

\section{Implications for training}

We propose that helping trainees with higher FS to build an awareness of their interpersonal style and associated strengths and vulnerabilities is an important part of training. We have found it valuable to offer trainees the opportunity to take a multi-trait multi-method personality assessment at the start of training. To protect student privacy, a clinician external to the program offers the assessment and provides feedback to the students. Although trainees have complete discretion as to whom they share the information with, in our experience, trainees often choose to share their results in supervision and report utilizing them in their own personal therapy. We believe this opportunity has helped many of our trainees cultivate insight into how their interpersonal tendencies may impact their practice. 
If trainees and/or their supervisors are aware of a trainee's friendly submissive tendencies, Bemak and Chung (2008) is a good source with which to consult. Importantly, Bemak and Chung (2008) emphasized that moving beyond Nice Counselor Syndrome requires that counselors avoid personalizing negative reactions and remain focused on higher level goals of their practice. Trainees higher in FS may be inclined to forget that a patient's expressions of discomfort and distress are often related to the difficult experiences that led him or her to seek therapy, and do not necessarily mean that the trainee is doing something wrong. Supervisors should remind trainees that helping patients explore and process negative emotions is tied to the higher goal of helping the patient to grow in ways that he or she deems important. These reminders will hopefully help trainees with higher levels of FS build an appropriate level of tolerance to uncomfortable feelings so that they are able to do the work that drives therapeutic change. In a similar vein, supervisors should emphasize the importance of collaborating with the patient to develop a mutually agreed upon focus for the therapy and checking in with patients about their understanding of the therapy. Although this process may involve disagreements, trainees should be reminded that interpersonal conflict comes with the territory and when handled effectively...can be healthy (Bemak \& Chung, 2008 , p. 379) and ultimately fuel patient growth. In conclusion, we hope that these recommendations can assist supervisors and their trainees in recognizing the ways in which interpersonal style can help or hinder the psychotherapy process.

\section{References}

Ackerman, S. J., \& Hilsenroth, M. J. (2001). A review of therapist characteristics and techniques negatively impacting the therapeutic alliance. Psychotherapy: Theory, Research, Practice, Training, 38(2), 171-185. doi:10.1037/00333204.38.2.171

Ackerman, S. J., \& Hilsenroth, M. J. (2003). A review of therapist characteristics and techniques positively impacting the therapeutic alliance. Clinical Psychology Review, 23(1), 133. doi:10.1016/S0272-7358(02)00146-0

Ackerman, S. J., Hilsenroth, M. J., Baity, M. R., \& Blagys, M. D. (2000). Interaction of therapeutic process and alliance during psychological assessment. Journal of Personality Assessment, 75(1), 82-109.

Alden, L. E., Wiggins, J. S., \& Pincus, A. L. (1990). Construction of circumplex scales for the Inventory of Interpersonal Problems. Journal of Personality Assessment, 55(3/4), 521536.

Anderson, T., Crowley, M. J., Himawan, L., Holmberg, J. K., \& Uhlin, B. D. (2016). Therapist facilitative interpersonal skills and training status: A randomized clinical trial on alliance and outcome. Psychotherapy Research, 26(5), 511529. doi: 10.1080/10503307.2015.1049671

Anderson, T., Ogles, B. M., Patterson, C. L., Lambert, M. J., \& Vermeersch, D. A. (2009). Therapist effects: Facilitative in- terpersonal skills as a predictor of therapist success. Journal of Clinical Psychology, 65(7), 755-768.

Baron, R. M., \& Kenny, D. A. (1986). The moderator-mediator variable distinction in social psychological research: Conceptual, strategic, and statistical considerations. Journal of Personality and Social Psychology, 51(6), 1173-1182.

Bemak, F., \& Chung, R. (2008). New professional roles and advocacy strategies for school counselors: A multicultural/social justice perspective to move beyond the Nice Counselor Syndrome. Journal of Counseling \& Development, 86(3), 372-382.

Beutler, L. E., Malik, M., Alimohamed, S., Harwood, T. M., Talebi, H., Noble, S., \& Wong, E. (2004). Therapist variables. In M. J. Lambert (Ed.), Bergin and Garfield's handbook of psychotherapy and behavior change (5th ed.) (pp. 227-306). New York, NY: John Wiley \& Sons.

Bordin, E. S. (1979). The generalizability of the psychoanalytic concept of the working alliance. Psychotherapy, 16(3), 252260.

Bornstein, R. F., \& Hopwood, C. J. (2017). Evidence-based assessment of interpersonal dependency. Professional Psychology: Research \& Practice, 48(4), 251-258. doi: $10.1037 /$ pro0000036

Castelnuovo-Tedesco, P. (1984). Psychotherapy and the fear of change. Psychiatric Journal of the University of Ottawa, 9(2), 67-70.

Castelnuovo-Tedesco, P. (1989). The fear of change and its consequences in analysis and psychotherapy. Psychoanalytic Inquiry, 9(1), 101-118. doi:10.1080/07351698909533757

Chapman, B. P., Talbot, N., Tatman, A. W., \& Britton, P. (2009). Personality traits and the working alliance in psychotherapy trainees: An organizing role for the Five Factor Model?. Journal of Social \& Clinical Psychology, 28(5), 577-596.

Cohen, J. (1988). Statistical power analysis for the behavioral sciences (2nd ed.). Hillsdale, NJ: Lawrence Erlbaum Associates.

Cooper, M., \& McLeod, J. (2007). A pluralistic framework for counselling and psychotherapy: Implications for research. Counselling \& Psychotherapy Research, 7(3), 135-143.

Dawood, S., Thomas, K. M., Wright, A. C., \& Hopwood, C. J. (2013). Heterogeneity of interpersonal problems among depressed young adults: Associations with substance abuse and pathological personality traits. Journal of Personality Assessment, 95(5), 513-522. doi:10.1080/00223891.2013.781031

Dinger, U., Zilcha-Mano, S., McCarthy, K. S., Barrett, M. S., \& Barber, J. P. (2013). Interpersonal problems as predictors of alliance, symptomatic improvement and premature termination in treatment of depression. Journal of Affective Disorders, 151(2), 800-803. doi:10.1016/j.jad.2013.07.003

Fluckiger, C., Del Re, A. C., Wampold, B. E., Symonds, D., \& Horvath, A.O. (2012). How central is the alliance in psychotherapy? A multilevel longitudinal meta-analysis. Journal of Counseling Psychology, 59(1), 10-17.

Hill, C. E. (2009). Helping skills: Facilitating exploration, insight and action (3rd ed.). Washington, DC: American Psychological Association.

Hill, C. E. (2014). Helping skills: Facilitating exploration, insight, and action (4th ed.). Washington, D.C.: American Psychological Association.

Hill, C. E., \& Kellems, I. S. (2002). Development and use of the helping skills measure to assess client perceptions of the effects of training and of helping skills in sessions. Journal of Counseling Psychology, 49(2), 264-272. https://doi.org/ 10.1037//0022-0167.49.2.264 
Hill, C. E., Stahl, J., \& Roffman, M. (2007). Training novice psychotherapists: Helping skills and beyond. Psychotherapy: Theory, Research, Practice, Training, 44(4), 364-370. doi:10.1037/0033-3204.44.4.364

Hilsenroth, M. J., Blagys, M. D., Ackerman, S. J., Bonge, D. R., $\&$ Blais, M. A. (2005). Measuring psychodynamic-interpersonal and cognitive-behavioral techniques: development of the comparative psychotherapy process scale. Psychotherapy, 42(3), 340-356.

Horowitz, L. M., Alden, L. E., Wiggins, J. S., \& Pincus, A. L. (2000). Inventory of Interpersonal Problems Manual. Odessa, FL: The Psychological Corporation.

Horowitz, L. M., Rosenberg, S. E., Baer, B. A., Ureño, G., \& Villaseñor, V. S. (1988). Inventory of interpersonal problems: Psychometric properties and clinical applications. Journal of Consulting and Clinical Psychology, 56(6), 885892. doi:10.1037/0022-006X.56.6.885

Horvath, A.O., Del Re, A. C., Fluckiger, C., \& Symonds, D. (2011). Alliance in individual psychotherapy. Psychotherapy, 48(1), 9-16.

Horvath, A. O., \& Greenberg, L. S. (1989). Development and validation of the Working Alliance Inventory. Journal of Counseling Psychology, 36(2), 223-233. doi:10.1037/00220167.36.2.223

Kiesler, D. J. (1996). Contemporary interpersonal theory \& research. New York, NY: John Wiley \& Sons, Inc.

Kivlighan, D. M. (2007). Where is the relationship in research on the alliance? Two methods for analyzing dyadic data. Journal of Counseling Psychology, 54(4), 423-433. doi:10.1037/0022-0167.54.4.423

Kivlighan, D. M., Marmarosh, C. L., \& Hilsenroth, M. J. (2014). Client and therapist therapeutic alliance, session evaluation, and client reliable change: A moderated actor-partner interdependence model. Journal of Counseling Psychology, 61(1), 15-23. doi:10.1037/a0034939

Lingiardi, V., Muzi, L., Tanzilli, A., \& Carone, N. (2018). Do therapists' subjective variables impact on psychodynamic psychotherapy outcomes? A systematic literature review. Clinical Psychology \& Psychotherapy, 25(1), 85-101. doi:10.1002/cpp.2131

Mallinckrodt, B. (1993). Session impact, working alliance, and treatment outcome in brief counseling. Journal of Counseling Psychology, 40(1), 25-32. doi:10.1037/0022-0167.40.1.25

Mallinckrodt, B., Porter, M. J., \& Kivlighan, D. J. (2005). Client attachment to therapist, depth of in-session exploration, and object relations in brief psychotherapy. Psychotherapy: Theory, Research, Practice, Training, 42(1), 85-100. doi:10.1037/0033-3204.42.1.85

Marks, I. M. (1989). Fears, phobias, and rituals: The nature of anxiety and panic disorders. New York: Oxford University Press.

McCullough, L., Kuhn, N., Andrews, S, Kaplan, A., Wolf, J., \& Hurley, C. L. (2003). Treating affect phobia: A manual for short-term dynamic psychotherapy. New York, NY: The Guilford Press.

Norcross, J.C., \& Wampold, B.E. (2011). Evidence-based ther- apy relationships: research conclusions and clinical practices. Psychotherapy, 48(1), 98-102.

Orlinsky, D. E., Schofield, M. J., Schroder, T., \& Kazantzis, N. (2011). Utilization of personal therapy by psychotherapists: A practice-friendly review and a new study. Journal of Clinical Psychology, 67(8), 828-842.

Pesale, F. P., \& Hilsenroth, M. J. (2009). Patient and therapist perspectives on session depth in relation to technique during psychodynamic psychotherapy. Psychotherapy: Theory, Research, Practice, Training, 46(3), 390-396. doi:10.1037/ a0016999

Regas, S. J., Kostick, K. M., Bakaly, J. W., \& Doonan, R. L. (2017). Including the self-of-the-therapist in clinical training. Couple and Family Psychology: Research and Practice, 6(1), 18-31. doi:10.1037/cfp0000073

Safran, J. D., \& Kraus, J. (2014). Alliance ruptures, impasses, and enactments: A relational perspective. Psychotherapy, 51(3), 381-387. doi:10.1037/a0036815

Saarnio, P. (2011). Therapists' big five personality traits and interpersonal functioning in the substance abuse field: A cluster-analytic study. Journal of Substance Use, 16(5), 348-358.

Shrout, P. E., \& Fleiss, J. L. (1979). Intraclass correlations: uses in assessing rater reliability. Psychological Bulletin, 86(2), 420-428.

Stiles, W. B., \& Snow, J. S. (1984). Counseling session impact as viewed by novice counselors and their clients. Journal of Counseling Psychology, 31(1), 3-12.

Stoltenberg, C.D., McNeill, B., \& Delworth, U. (1998). IDM supervision: An integrated developmental model for supervising counselors and therapists. San Francisco: Jossey Bass.

Topolinski, S., \& Hertel, G. (2007). The role of personality in psychotherapists' careers: Relationships between personality traits, therapeutic schools, and job satisfaction. Psychotherapy Research, 17(3), 378-390.

Tryon, G. S. (1990). Session depth and smoothness in relation to the concept of engagement in counseling. Journal of Counseling Psychology, 37(3), 248-253. doi:10.1037/00220167.37.3.248

Wachtel, P. L. (1977). Psychoanalysis and behavior therapy. New York, NY: Basic Books.

Wachtel, P. L. (1991). From eclecticism to synthesis: Toward a more seamless psychotherapeutic integration. Journal of Psychotherapy Integration, 1(1), 43-54.

Wachtel, P. L. (1993). Therapeutic communication: Principles and effective practice. New York, NY: The Guilford Press.

Wachtel, P. L. (2008). Relational theory and the practice of psychotherapy. New York, NY: The Guilford Press.

Weeks, J. W., Heimberg, R. G., \& Heuer, R. (2011). Exploring the role of behavioral submissiveness in social anxiety. Journal of Social \& Clinical Psychology, 30(3), 217-249.

Zilcha-Mano, S., \& Errázuriz, P. (2017). Early development of mechanisms of change as a predictor of subsequent change and treatment outcome: The case of working alliance. Journal of Consulting and Clinical Psychology, 85(5), 508-520. doi:10.1037/ccp0000192 